\title{
MAO A VNTR polymorphism and amygdala volume in healthy subjects
}

\author{
Antonio Cerasa $^{\mathrm{a}, *}$, Aldo Quattrone ${ }^{\mathrm{a}, \mathrm{c}}$, Maria C. Gioia ${ }^{\mathrm{a}, \mathrm{g}}$, Angela Magariello ${ }^{\mathrm{b}}$, Maria Muglia ${ }^{\mathrm{b}}$, \\ Francesca Assogna d, Sergio Bernardini e, Carlo Caltagirone ${ }^{\mathrm{d}, \mathrm{f}}$, Paola Bossù d, Gianfranco Spalletta ${ }^{\mathrm{d}}$ \\ ${ }^{a}$ Neuroimaging Research Unit, Institute of Neurological Sciences, National Research Council, Catanzaro Italy \\ b Institute of Neurological Sciences, National Research Council, Piano Lago di Mangone, Cosenza, Italy \\ c Institute of Neurology, University "Magna Graecia", Catanzaro, Italy \\ d IRCCS Santa Lucia Foundation, Rome, Italy \\ e Tor Vergata" University, Dept. of Laboratory Medicine, Rome, Italy \\ ${ }^{\mathrm{f}}$ Tor Vergata" University, Dept. of Neuroscience, Rome, Italy \\ ${ }^{g}$ Evolutionary Systems Group, University of Calabria, Arcavacata di Rende, Cosenza, Italy
}

\section{A R T I C L E I N F O}

\section{Article history:}

Received 12 August 2010

Received in revised form 2 November 2010

Accepted 2 November 2010

\section{Keywords:}

MAO A variable number of tandem repeats

(VNTR) genotype

Amygdala volume

Automated subcortical segmentation

Imaging genetics

\begin{abstract}
A B S T R A C T
The X-linked Monoamine Oxidase A (MAO A) gene presents a well known functional polymorphism consisting of a variable number of tandem repeats (VNTR) (long and short variants) previously associated with altered neural function of the amygdala. Using automatic subcortical segmentation (Freesurfer), we investigated whether amygdala volume could be influenced by this genotype. We studied 109 healthy subjects (age range 18-80 years; 59 male and 50 female), 74 carrying the MAO A High-activity allele and 35 the MAO A Low-activity allele. No significant effect of the MAO A polymorphism or interaction effect between polymorphism $\times$ gender was found on amygdalar volume. Thus, our findings suggest that the reported impact of the MAO A polymorphism on amygdala function is not coupled with consistent volumetric changes in healthy subjects. Future studies are needed to investigate whether the association between volume of the amygdala and the MAO A VNTR polymorphism is influenced by social/psychological variables, such as impulsivity, trauma history and cigarette smoking behaviour, not taken into account in this work.
\end{abstract}

(c) 2010 Elsevier Ireland Ltd. All rights reserved.

\section{Introduction}

The amygdala is a deep grey matter brain structure involved in emotional processing and is densely innervated by serotonergic (5hydroxytryptamine; 5-HT) neurons (Azmitia and Gannon, 1986). Catabolism of 5-HT is regulated by the activity of the monoamine oxidase (MAO) enzyme, with the isoform MAO A having a much greater affinity for the substrate than the isoform MAO B (Shih and Chen, 1999). The MAO A coding gene (Xp11.4-Xp11.3) presents a well-characterized functional polymorphism consisting of a variable number of tandem repeats (VNTR) in the promoter region with different length variants that selectively influence the protein transcription and, hence, the enzymatic activity (Denney et al., 1999). Enzyme expression is relatively high for carriers of 3.5 or 4 repeats (MAO A High) and is lower for carriers of 2, 3 or 5 repeats (MAO A Low) (Sabol et al., 1988). Several studies found a significant association between this functional genotype and personality traits such as aggression and impulsivity (Caspi et al., 2002; Foley et al., 2004), suggesting a deficiency in the neural systems for emotional

\footnotetext{
* Corresponding author. Neuroimaging Research Unit, Institute of Neurological Sciences, National Research Council, 88100, Germaneto (CZ), Italy. Tel.: +390984 9801766; fax: +390984969306.

E-mail address: a.cerasa@isn.cnr.it (A. Cerasa).
}

regulation. At the present time, the neurobiological mechanisms underlying the effect of this polymorphism are still unclear.

Imaging genetics is a novel approach aimed to characterize the influence of genes on individual variability in cognition and behaviour. It is based on the assumption that brain structure and function are more closely related to gene function than trait differences in overt behaviour (Mattay et al., 2008). Thus, the study of the "intermediate phenotype" might provide a more direct measurement of the impact of a gene.

Recent imaging genetic studies investigating healthy individuals have begun to elucidate the neurobiological mechanisms by which heritable variation in MAO A impacts neural circuitry involved in emotion regulation, demonstrating a clear effect on mediating amygdala function (Meyer-Lindenberg et al., 2006; Buckholtz et al., 2008; Alia-Klein et al., 2009). Although there is consistent evidence that the MAO A polymorphism impacts limbic function, possible morphological changes underlying such a functional polymorphism remain to be clarified. In fact, there are few morphological studies that, using voxel-based morphometry (VBM), indirectly investigated the association of this genotype with amygdala volume, and these studies produced contrasting findings (Meyer-Lindenberg et al., 2006; Cerasa et al., 2008b). VBM is a morphological technique that performs a statistical mapping of differences in brain morphology voxel-byvoxel, which produces grey matter "density" or "concentration" measures, or volume differences between two groups, respectively; 
however, these are relative measures and not absolute volumes (Eckert et al., 2006; Makris et al., 2008). Alternatively, manual/ automatic volumetry is a quantitative measurement of specific brain regions in individual brains.

For this reason, the aim of this study is to provide direct evidence of the association between the MAO A VNTR polymorphism and amygdala volumetry by using a relatively new fully automated segmentation labelling algorithm (Freesurfer) (Fischl et al., 2002). This software is a highly reliable method for automated MRI-based measurements of human brain volumes that provides novel insights into abnormal neuroanatomy and may be a useful tool for the investigation of brain changes in imaging genetics studies (Monuteaux et al., 2008; Ehrlich et al., 2010). The segmentation method provided by this software directly subdivides the image into a series of neuroanatomically defined structures with a priori knowledge of their individual intensity properties, atlas location and location relative to each other.

\section{Methods and materials}

\subsection{Subjects}

From May 2007 to February 2010, 163 right-handed healthy Caucasian individuals were recruited by local advertisements. Inclusion criteria were age between 18 and 80 and no neuropsychiatric or major physical illnesses. Exclusion criteria were (1) major medical illnesses and/or known or suspected history of alcoholism or drug dependency and abuse; (2) mental disorders (i.e., mood, anxiety, personality and/or any other significant mental disorders) according to the DSM-IV criteria assessed by the Structured Clinical Interviews for DSM-IV Axis I (SCID-I) (First et al., 1997a) and Axis II (SCID-II) (First et al., 1997b) and/or neurological disorders diagnosed by an accurate clinical neurological examination; (3) heterozygosis in women. MAO A is an X-linked gene; thus, males are homozygous carriers of either one MAO A High-activity allele or one MAO A Lowactivity allele, whereas women carry two alleles. Therefore, only women can be heterozygous. Since the cellular mechanisms concerning enzymatic activity in heterozygous females are not currently known (Meyer-Lindenberg et al., 2006), we included only homozygotic females; (4) presence of vascular brain lesions, brain tumour and/or marked cortical and/or subcortical atrophy (such as hippocampus, Labate et al., 2010) on MRI scan. In fact, two expert radiologists examined all MRIs to exclude potential brain abnormalities as apparent in conventional FLAIR and T2-weighted and T1weighted images; and (5) presence of dementia. We included only subjects with a Mini Mental State Examination (MMSE; Folstein et al., 1975) score of at least 24 points (a cutoff point for dementia screening in the Italian population according to Measso et al., 1993) or if they did not present a dementia diagnosis according to DSM-IV criteria.

After a careful evaluation of these exclusion criteria, 54 subjects were excluded from the study. The 109 subjects (mean \pm S.D. age $=41.5 \pm$ $15.3,59$ male, 50 female subjects) included were classified on the basis of the High-activity ( $n=74 ; 3.5$ or 4 repeats) and the Low-activity ( $n=35 ; 2,3$ or 5 repeats) allelic variants of the MAO A VNTR polymorphism. The male populations had taken part in our previous imaging genetics study (Cerasa et al., 2010). Written, informed consent was obtained from all subjects participating in the study, which was approved by the local ethics committee at Santa Lucia Foundation of Rome, in accordance with the guidelines of the Helsinki Declaration (1983).

\subsection{Genotyping}

DNA was extracted from blood samples obtained from all subjects according to standard procedures. Genotyping for the MAO A VNTR polymorphism was performed as described previously (Furlong et al., 1999; Passamonti et al., 2006; Passamonti et al., 2008; Cerasa et al., 2008a,b; Cerasa et al., 2010). Briefly, the VNTR promoter MAO A polymorphism was amplified from genomic DNA using primers designed by the Web Primer site (http://www.seq.yeastgenome.org/ cgi-bin/web-primer) that flanked the polymorphic region located approximately $1200 \mathrm{bp}$ upstream from the translation start site (Furlong et al., 1999) (GeneBank accession number AJ004833). Sequences of the primers are as follows: MAO A forward: 5'CCAGAAACATGAGCACAAACG-3', and MAO A reverse: 5'-ATTCGGA CAGGCTGTAGGAG-3'. The forward primer was labelled with FAM fluorophore. Polymerase chain reaction (PCR) was carried out in a final volume of $25 \mu \mathrm{l}$ including $200 \mathrm{ng}$ of genomic DNA, $12 \mathrm{pmol}$ of each primer, $200 \mu \mathrm{M}$ of dNTPs, $1.5 \mathrm{mM}$ of $\mathrm{MgCl}_{2}$ and $1 \mathrm{U}$ of Taq DNA polymerase (Promega, Madison, WI, USA). Cycling conditions started with an initial denaturation at $94^{\circ} \mathrm{C}$ for $3 \mathrm{~min}$, followed by $30 \mathrm{~s}$ at $94^{\circ} \mathrm{C}$, $45 \mathrm{~s}$ at $58^{\circ} \mathrm{C}$ and $60 \mathrm{~s}$ at $72^{\circ} \mathrm{C}$ for 30 cycles, with a final extension at $72^{\circ} \mathrm{C}$ for $4 \mathrm{~min}$. The PCR products were mixed with $1.5 \mu \mathrm{l}$ of formamide, $0.5 \mu \mathrm{l}$ of loading buffer, $0.5 \mu \mathrm{l}$ of fluorescently labelled size standard GENESCAN 350-TAMRA and then electrophoresed for $150 \mathrm{~min}$ in the ABI automated DNA sequencer 377 (Applied Biosystem, Foster City, CA). Data were collected and analysed using the ABI GENESCAN 672 software (Applied Biosystem, Foster City, CA).

\subsection{MRI sequence and analysis}

Each of the 109 participants underwent the same imaging protocol with a whole-brain T1-weighted scan using a 3 T Allegra MR imager (Siemens, Erlangen, Germany) with a standard quadrature head coil. Whole-brain T1-weighted images were obtained in the sagittal plane using a modified driven equilibrium Fourier transform (MDEFT) (Deichmann et al., 2004) sequence (TE/TR $=2.4 / 7.92 \mathrm{~ms}$, flip angle $15^{\circ}$, voxel-size $1 \times 1 \times 1 \mathrm{~mm}^{3}$ ). Subcortical volume analysis was measured automatically with FreeSurfer 4.05 installed on a Red Hat Enterprise Linux v.5. The automated procedures for volumetric measures of these several subcortical regions have been previously described (Fischl et al., 2002). This procedure automatically provided segments and labels for up to 40 unique structures and assigned a neuroanatomical label to each voxel in an MRI volume based on probabilistic information estimated automatically from a manually labelled training set. Briefly, the segmentation is performed as follows: an optimal linear transform is computed that maximizes the likelihood of the input image, given an atlas constructed from manually labelled images. A nonlinear transform is then initialized with the linear one, and the image is allowed to further deform to better match the atlas. Finally, a Bayesian segmentation procedure is performed, and the maximum a posteriori estimate of the labelling is computed. The segmentation uses three pieces of information to disambiguate labels: 1) the prior probability of a given tissue class occurring at a specific atlas location, 2) the likelihood of the image given that tissue class and 3) the probability of the local spatial configuration of labels given the tissue class. This latter term represents a large number of constraints on the space of allowable segmentations and prohibits label configurations that never occur in the training set (e.g., the hippocampus is never anterior to the amygdala). This approach provides advantages similar to manual region-of-interest (ROI) drawing (Morey et al., 2009; Jovicich et al., 2009), without the potential for rater bias, offering an anatomically accurate rendering of regional volumes (Fischl et al., 2002). The entire cortex in each individual subject was visually inspected prior to analysis and, if needed, manually edited. These processes involved: a) realignment of each subject's image to the MNI template; b) setting intensity normalization control points where brain matter was erroneously skull stripped; c) adjustment watershed parameters of the skull strip and d) visual inspection and correction of the automatic subcortical segmentation. All subjects were inspected by a neuroradiologist with a high level of neuroanatomical expertise, who was blinded to the MRI results. Five subjects (two excluded for dementia and three excluded for brain lesions) had MRIs of inferior quality, not suitable for 
Table 1

Sociodemographical and amygdala volumetric characteristics of 109 healthy Caucasian subjects carrying different MAO A VNTR genotypes.

\begin{tabular}{|c|c|c|c|c|c|c|c|}
\hline Demographic data & $\begin{array}{l}\text { Male MAO A } \\
\text { high-activity }\end{array}$ & $\begin{array}{l}\text { Female MAO A } \\
\text { high-activity }\end{array}$ & $\begin{array}{l}\text { Male MAO A } \\
\text { low-activity }\end{array}$ & $\begin{array}{l}\text { Female MAO A } \\
\text { low-activity }\end{array}$ & $\begin{array}{l}\text { Allele } F \\
(p)\end{array}$ & $\begin{array}{l}\text { Gender } F \\
(p)\end{array}$ & $\begin{array}{l}\text { Allele by gender } F \\
(p)\end{array}$ \\
\hline No. & 36 & 38 & 23 & 12 & & & \\
\hline Age (years) & $37.8 \pm 13.9$ & $41.5 \pm 16.1$ & $41.9 \pm 16.7$ & $43.5 \pm 19.4$ & $0.37^{\mathrm{a}}$ & $0.46^{\mathrm{a}}$ & $0.76^{\mathrm{a}}$ \\
\hline Educational level (years) & $13(8-19)$ & $16(8-24)$ & $13(11-21)$ & $13(5-21)$ & $0.94^{\mathrm{b}}$ & $0.93^{\mathrm{b}}$ & $0.17^{\mathrm{b}}$ \\
\hline MMSE & $29.7 \pm 0.5$ & $29.2 \pm 1.2$ & $28.9 \pm 1.2$ & $29 \pm 1.5$ & $0.1^{\mathrm{a}}$ & $0.29^{\mathrm{a}}$ & $0.27^{\mathrm{a}}$ \\
\hline ICV & $1475.5 \pm 127$ & $1317.5 \pm 122.4$ & $1506 \pm 96.5$ & $1263.1 \pm 97.4$ & $0.64^{\mathrm{a}}$ & $<0.001^{\mathrm{a}}$ & $0.11^{\mathrm{a}}$ \\
\hline Left amygdala $\left(\mathrm{cm}^{3}\right)$ & $1.367 \pm 0.22$ & $1.233 \pm 0.17$ & $1.413 \pm 0.19$ & $1.153 \pm 0.15$ & $0.84^{\mathrm{c}}$ & $0.05^{\mathrm{c}}$ & $0.26^{\mathrm{c}}$ \\
\hline Right amygdala $\left(\mathrm{cm}^{3}\right)$ & $1.555 \pm 0.24$ & $1.345 \pm 0.22$ & $1.497 \pm 0.22$ & $1.253 \pm 0.19$ & $0.16^{\mathrm{c}}$ & $0.08^{\mathrm{c}}$ & $0.88^{\mathrm{c}}$ \\
\hline
\end{tabular}

Data are given as mean values (S.D.) or median values (range) when appropriate. MMSE, Mini Mental State Examination; ICV, intracranial volume.

a ANOVA.

b Mann-Whitney test.

c ANCOVA corrected for ICV and age.

reliable tissue segmentation with Freesurfer even after manual editing of cortical surface and subcortical regions. Intracranial volume (ICV) was calculated and used to correct the regional brain volumes analyses (Buckner et al., 2004). ICV includes biological material such as meninges and cerebrospinal fluid in addition to brain tissue.

To confirm the validity of our data, we performed a further analysis characterizing well-defined volumetric changes in human healthy brain. In particular, we investigated volumetry in subcortical regions in association with aging to confirm the expected linear relationship (Walhovd et al., 2005; Cherubini et al., 2009) (see Supplemental Materials).

\subsection{Statistical analysis}

Statistical analyses were performed with Statistical Package for Social Sciences software-SPSS (version 12.0, Chicago IL, USA). Estimation of the statistical power has been performed. For this calculation, we include the pooled mean and S.D. of amygdala volume for each genotype group, together with sample size. For all sample size estimates, a significance level of 0.01 was assumed. Power calculation (http://www.dssresearch.com/toolkit/spcalc/power_a2. asp) revealed that the sample size was sufficient to reach a statistical power of $96.1 \%$ (4.1\% risk of type II errors) at a significance level of $\alpha<0.01$. Moreover, the Cohen's $d$ (Cohen, 1998) was calculated as a measure of the effect sizes, which indicates the magnitude of mean differences (using the estimated marginal means) in S.D. units.

Assumptions for normality were tested for all continuous cognitive and demographic variables. Normality was tested using the Kolmogorov-Smirnov test. All variables were normally distributed, except for the number of years of formal education $(K-S=0.2, p<0.05)$. Analysis of variance, Mann-Whitney $U$-test (educational level) and $\chi^{2}$ (genotype distributions) were used to assess potential differences between the genotype groups for all demographic variables. To assess both the main effects of allelic variants (High or Low activity) and gender (male versus female) and the interactive effects between these factors on amygdala volume, we used analysis of covariance (ANCOVA) with ICV and age as nuisance variables. All statistical analyses had a 2-tailed $\alpha$ level of less than 0.01 for defining significance.

\section{Results}

Sociodemographic and global cognitive level variables were well matched between groups. ICV differed significantly between males and females, which did not influence the analyses because this was addressed by adding ICV as a covariate in the analyses. The genotype distribution in our samples was in Hardy-Weinberg equilibrium $\left(\chi^{2}=0.17 ; p=0.98\right)$.

No allele (respectively, right side: $F_{1,103}=1.96, p=0.16$; Cohen's $d=0.40$; left side: $F_{1,103}=0.037, p=0.84$; Cohen's $d=0.006$ ) or allele $\times$ gender interactive effects (respectively, right side: $F_{1,103}=0.02$, $p=0.88$; Cohen's $d=0.001$; left side: $F_{1,103}=1.27, p=0.26$; Cohen's $d=0.26$ ) were found in volumetric data (see Table 1 and Fig. 1), whereas the main effect of gender was at the borderline of significance in both amygdalae (respectively, right side: $F_{1,103}=3.33, p=0.079$; Cohen's $d=0.67$; left side: $F_{1,103}=4.18, p=0.049$; Cohen's $d=0.82$ ).

Given the slight effect of gender on amygdalae volume, we reanalyzed the data using gender as a covariate. No significant changes were detected in the bilateral amygdalae as a function of MAO A polymorphism (respectively, right side: $F_{1}, 104=2.16$, $p=0.14$; Cohen's $d=0.44$; left side: $F_{1,104}=0.02, p=0.95$; Cohen's $d=0.004)$.
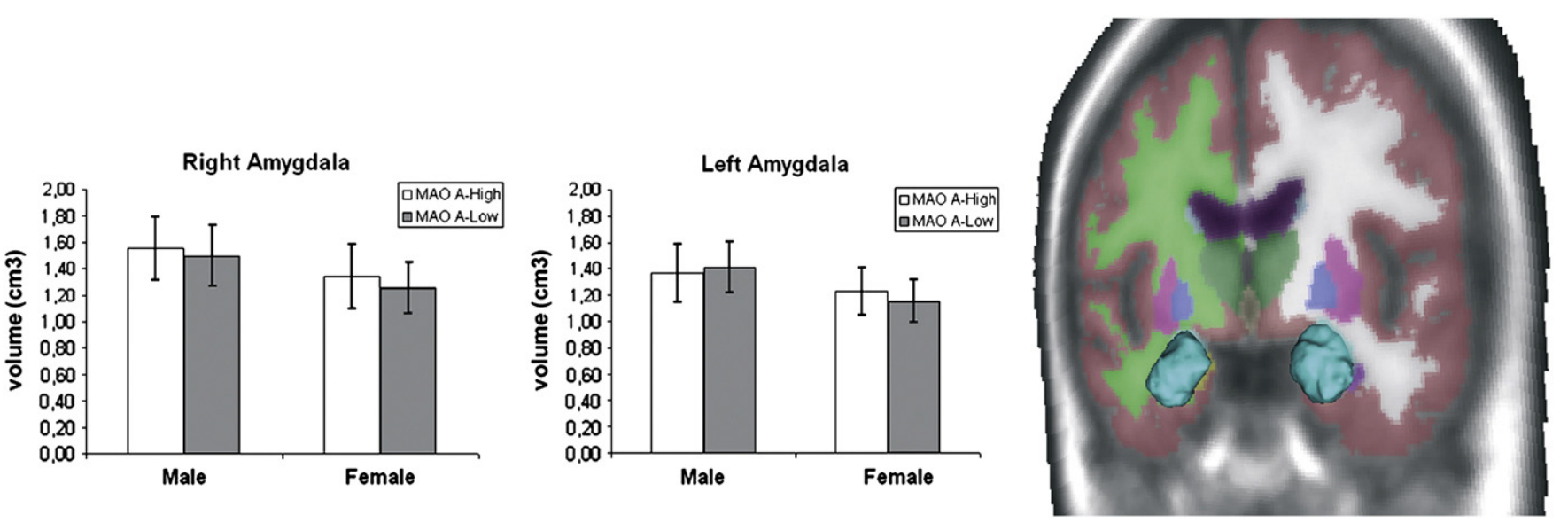

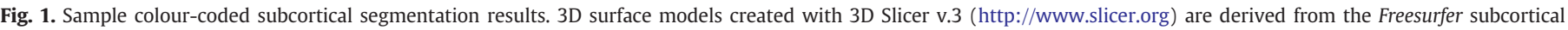

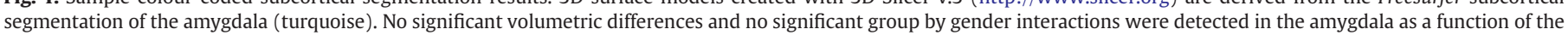

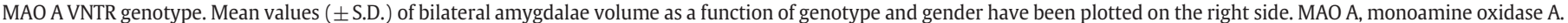




\section{Discussion}

Our study demonstrates that the MAO A VNTR polymorphism is not associated with amygdala volumetric changes in a large sample of healthy individuals.

In animals, from a physiological point of view, MAO A enzymatic activity is particularly relevant to amygdala functions (Lesch and Merschdorf, 2000). Furthermore, the sex hormone receptors are prominently expressed in the amygdala and able to influence monoamine metabolism by regulating MAO A mRNA expression (Gundlah et al., 2002). Mouse knockouts for MAO A show enhanced amygdala-dependent emotional learning (Kim et al., 1997), and male mice exhibit dramatically increased aggressive behaviour (Cases et al., 1995). In humans, there are studies using functional MRI that confirm that genetic variants in the serotonergic system impact amygdala response. In particular, carriers of the MAO A Low-activity allele exhibit increased neurofunctional activity of the amygdala during emotional processing (Meyer-Lindenberg et al., 2006; Buckholtz et al., 2008; AliaKlein et al., 2009) in comparison with their respective High-activity counterparts. Our structural findings suggest that the well-defined influence of the MAO A genetic variant on amygdala function is not mirrored by macrostructural anatomical changes.

Our data pose important new questions about the neurobiological impact of the MAO A polymorphism on the human brain. Generally, this genotype has a profound impact on both neuroanatomy and functional activity of two specific brain regions, critically involved in emotional processing and aggressive behaviour: the orbitofrontal cortex (Meyer-Lindenberg et al., 2006; Passamonti et al., 2006; Passamonti et al., 2008; Buckholtz et al., 2008; Cerasa et al., 2008a,b) and the cingulate cortex (Meyer-Lindenberg et al., 2006; Passamonti et al., 2008). By contrast, this combined neuroanatomical/functional impact of the MAO A VNTR polymorphism is not evident in the amygdala. Thus, it is possible to hypothesize the presence of further neurobiological effects as a function of this genotype. In fact, while the altered neurofunctional responses in the orbitofrontal and cingulate cortices were reported as a single event (carriers of the MAO A Highactivity allele showed higher activity with respect to Low-activity counterparts), the detected functional change in the amygdala has been reported as an altered functional connectivity between this region with other limbic regions (such as the orbitofrontal cortex, Buckholtz et al., 2008). Thus, it could be more likely that anatomical volume would not be a useful intermediate phenotype in determining the effect of the MAO A genotype on the amygdala. Different MRI parameters, such as microstructural changes measured by diffusion tensor Imaging or structural brain connectivity should be investigated for this purpose (Marenco and Radulescu, 2010).

Another important finding of our study is that the impact of the MAO A VNTR polymorphism on amygdala volume is not influenced by gender. MAO A is an X-chromosomal gene; it is possible that gene dosage differences between men and women due to incomplete $\mathrm{X}$ inactivation could underlie the predominant effect on males. However, our data are completely in agreement with a previous study showing that the effect of the MAO A genotype on several parameters of neural activation and structure was very similar in both genders, suggesting that different gene dosages are unlikely to be the single underlying cause (Meyer-Lindenberg et al., 2006; Buckholtz et al., 2008).

Three important caveats of this study need to be discussed. The automated procedure employed in this study (Freesurfer) has limitations. In fact, given the inherent limitations of any fully automated segmentation software, cortical and subcortical labelling may be influenced by several factors, such as section thickness, MRI noise level, field strength, MRI signal intensities in elderly subjects and anatomic boundary criteria. However, recent methodological studies (Morey et al., 2009; Jovicich et al., 2009) have demonstrated that Freesurfer can be considered an acceptable substitute for manual tracing of automatically quantified amygdala volume, although a large cohort of subjects is warranted. Second, the lack of a significant association between amygdala volume and MAO A VNTR polymorphism could be influenced by further social/psychological variables not taken into consideration in this work, such as impulsivity (Soloff et al., 2008), social disadvantage experiences such as trauma or abuse history (Caspi et al. 2002, Kim-Cohen et al. 2006) or cigarette smoking behaviour (Caporaso et al., 2009) that could ultimately interact with MAO A functioning. In particular, the association between variants in MAO gene region and cigarette smoking behaviour is notable because of the role of the monoamine oxidases in the regulation of catecholamines and the inhibition of MAO A and B by tobacco smoke (Fowler et al., 2003). There is substantial evidence that smoking results in reduced levels of the MAO enzymes (Fowler et al., 2003) and subsequent reduced catabolism of dopamine likely contributes to the reinforcing and motivating effects of smoking. Thus the effect of this variable on the reported morphological endophenotype needs to be investigated. Finally, in this study we did not consider the epistatic effects of additional genetic variants that have been demonstrated to affect amygdala volume, such as the 5hydroxytryptamine 1A (5-HT1A) receptor gene C-1019G polymorphism (Zetzsche et al. 2008) and the catechol-O-methyltransferase (COMT) gene Val ${ }^{108}$ Met polymorphism (Ehrlich et al., 2010).

Our data are discrepant to a previous imaging genetics study, which reported significant association between MAO A polymorphism and amygdala grey matter concentration (Meyer-Lindenberg et al., 2006). Different results might depend upon the different MRI volumetric approach employed by Meyer-Lindenberg et al. (2006) (VBM), although in an our previous VBM study using an underpowered sample we did not detect significant association between MAO A and amygdala concentration (Cerasa et al., 2008b). Generally, VBM and volumetric studies often are not directly comparable. For instance, areas that show significant age effects using VBM are unlikely to correspond exactly to regions of interest investigated in a volumetric study (Tisserand et al., 2002; Allen et al., 2005). VBM is a classical MRI statistical method where the local amount of brain tissue is simply measured as the intensity within each voxel and can be influenced by several methodological issues such as degree of smoothing, differences in registration, choice of normalization template and modulation step (Ashburner and Friston, 2001; Eckert et al., 2006). On the other hand, manual/automatic volumetry is a quantitative research tool that captures a real physical quantity that could not reach the specificity of small changes (voxel-level). Another possible explanation for the contrasting results between our study and those of Meyer-Lindenberg et al. (2006) may have been due to the different age compositions of the subject populations. In fact, in our study we investigated healthy subjects with a wide age range (18-80 years), whereas Meyer-Lindenberg et al. (2006) investigated younger individuals. As widely recognized, normal aging is accompanied by global as well as regional structural changes (Walhovd et al., 2005; Allen et al., 2005) that, ultimately, might explain discrepancies with respect to findings provided by Meyer-Lindenberg et al. (2006).

\section{Conclusions}

In summary, this imaging genetics study demonstrated that there are no allele or allele $\times$ gender interaction effects on amygdala volume in healthy Caucasian humans, thus suggesting that the MAO A VNTR polymorphism has a limited effect focused on the amygdala function (Meyer-Lindenberg et al., 2006; Buckholtz et al., 2008; Alia-Klein et al., 2009). The sample size employed in this study had $96.1 \%$ power to detect significant difference in amygdala volume between the genotype groups (assuming alpha $=0.01$ ). Further studies should use different structural MRI parameters to investigate a possible association between amygdala anatomy and MAO A polymorphism. 


\section{Acknowledgements}

We wish to thank all participants for their time and interest in this study and Erin McCloskey for editing the English.

\section{Appendix A. Supplementary data}

Supplementary data to this article can be found online at doi:10.1016/j.pscychresns.2010.11.002.

\section{References}

Alia-Klein, N., Goldstein, R.Z., Tomasi, D., Woicik, P.A., Moeller, S.J., Williams, B., Craig, I.W. Telang, F., Biegon, A., Wang, G.J., Fowler, J.S., Volkow, N.D., 2009. Neural mechanisms of anger regulation as a function of genetic risk for violence. Emotion 9, 385-396.

Allen, J.S., Bruss, J., Brown, C.K., Damasio, H., 2005. Methods for studying the aging brain: volumetric analyses versus VBM. Neurobiology of Aging 26, 1275-1278.

Azmitia, E.C., Gannon, P.J., 1986. The primate serotonergic system: a review of human and animal studies and a report on Macaca fascicularis. Advances in Neurology 43, 407-468.

Ashburner, J., Friston, K.J., 2001. Why voxel-based morphometry should be used. Neuroimage 14, 1238-1243.

Buckner, R.L., Head, D., Parker, J., Fotenos, A.F., Marcus, D., Morris, J.C., Snyder, A.Z., 2004 A unified approach for morphometric and functional data analysis in young, old, and demented adults using automated atlas-based head size normalization: reliability and validation against manual measurement of total intracranial volume. Neuroimage 23, 724-738.

Buckholtz, J.W., Callicott, J.H., Kolachana, B., Hariri, A.R., Goldberg, T.E., Genderson, M. Egan, M.F., Mattay, V.S., Weinberger, D.R., Meyer-Lindenberg, A., 2008. Genetic variation in MAO A modulates ventromedial prefrontal circuitry mediating individual differences in human personality. Molecular Psychiatry 13, 313-324.

Caporaso, N., Gu, F., Chatterjee, N., Sheng-Chih, J., Yu, K., Yeager, M., Chen, C., Jacobs, K., Wheeler, W., Landi, M.T., Ziegler, R.G., Hunter, D.J., Chanock, S., Hankinson, S., Kraft, P., Bergen, A.W., 2009. Genome-wide and candidate gene association study of cigarette smoking behaviors. PLoS ONE 4, e4653.

Cases, O., Seif, I., Grimsby, J., Gaspar, P., Chen, K., Pournin, S., Müller, U., Aguet, M., Babinet, C., Shih, J.C., 1995. Aggressive behavior and altered amounts of brain serotonin and norepinephrine in mice lacking MAO A. Science 268, 1763-1766.

Caspi, A., McClay, J., Moffitt, T.E., Mill, J., Martin, J., Craig, I.W., Taylor, A., Poulton, R., 2002. Role of genotype in the cycle of violence in maltreated children. Science 297, 851-854.

Cerasa, A., Cherubini, A., Quattrone, A., Gioia, M.C., Magariello, A., Muglia, M., Manna, I. Assogna, F., Caltagirone, C., Spalletta, G., 2010. Morphological correlates of MAO A VNTR polymorphism: new evidence from cortical thickness measurement. Behavioural Brain Research 211, 118-124.

Cerasa, A., Gioia, M.C., Fera, F., Passamonti, L., Liguori, M., Lanza, P., Muglia, M., Magariello, A., Quattrone, A., 2008a. Ventro-lateral prefrontal activity during working memory is modulated by MAO A genetic variation. Brain Research 1201, 114-121.

Cerasa, A., Gioia, M.C., Labate, A., Lanza, P., Magariello, A., Muglia, M., Quattrone, A 2008b. MAO A VNTR polymorphism and variation in human morphology: a VBM study. NeuroReport 19, 1107-1110.

Cherubini, A., Péran, P., Caltagirone, C., Sabatini, U., Spalletta, G., 2009. Aging of subcortical nuclei: microstructural, mineralization and atrophy modifications measured in vivo using MRI. Neuroimage 48, 29-36.

Cohen, J., 1998. Statistical power analysis for the behavioral sciences, 2nd ed. Lawrence Earlbaum Associates, Hillsdale, NJ.

Deichmann, R., Schwarzbauer, C., Turner, R., 2004. Optimisation of the 3D MDEFT sequence for anatomical brain imaging: technical implications at 1.5 and $3 \mathrm{~T}$. Neuroimage 21, 757-767

Denney, R.M., Koch, H., Craig I.W. 1999. Association between monoamine oxidase A activity in human male skin fibroblasts and genotype of the MAO-A promoterassociated variable number of tandem repeats. Human Genetics 105, 542-551.

Eckert, M.A., Tenforde, A., Galaburda, A.M., Bellugi, U., Korenberg, J.R., Mills, D., Reiss, A. L., 2006. To modulate or not to modulate: differing results in uniquely shaped Williams syndrome brains. Neuroimage 32, 1001-1017.

Ehrlich, S., Morrow, E.M., Roffman, J.L., Wallace, S.R., Naylor, M., Bockholt, H.J., Lundquist, A. Yendiki, A., Ho, B.C., White, T., Manoach, D.S., Clark, V.P., Calhoun, V.D., Gollub, R.L., Holt, D.J., 2010. The COMT Val108/158Met polymorphism and medial temporal lobe volumetry in patients with schizophrenia and healthy adults. Neuroimage 53, 992-1000.

First, M.B., Gibbon, M., Spitzer, R.L., Williams, J.B.W., Benjamin, L.S., 1997a. Structured Clinical Interview for DSM-IV Axis II Personality Disorders (SCID-II): Clinician Version. American Psychiatric Press, Washington.

First, M.B., Spitzer, R.L., Gibbon, M., Williams, J.B.W., 1997b. Structured Clinica Interview for DSM-IV Axis I Disorders (SCID-I): Clinician Version. American Psychiatric Press, Washington.

Fischl, B., Salat, D.H., Busa, E., Albert, M., Dieterich, M., Haselgrove, C., van der Kouwe, A Killiany, R., Kennedy, D., Klaveness, S., Montillo, A. Makris, N., Rosen, B., Dale, A.M. 2002. Whole brain segmentation: automated labelling of neuroanatomical structures in the human brain. Neuron 33, 341-355.

Foley, D.L., Eaves, L.J., Wormley, B., Silberg, J.L., Maes, H.H., Kuhn, J., Riley, B., 2004 Childhood adversity, monoamine oxidase a genotype, and risk for conduct disorder. Archives of General Psychiatry 61, 738-744.
Folstein, M.F., Folstein, S.E., McHugh, P.R., 1975. Mini-mental state. A practical method for grading the cognitive state of patients for the clinician. Journal of Psychiatric Research 12, 189-198.

Fowler, J.S., Logan, J., Wang, G.J., Volkow, N.D., 2003. Monoamine oxidase and cigarette smoking. Neurotoxicology 24, 75-82.

Furlong, R.A., Ho, L., Rubinsztein, J.S., Walsh, C., Paykel, E., Rubinsztein, D.C., 1999. Analysis of the monoamine oxidase A (MAO A) gene in bipolar affective disorder by association studies, meta-analyses, and sequencing of the promoter. American Journal of Medical Genetics 88, 398-406.

Gundlah, C., Lu, N.Z., Bethea, C.L., 2002. Ovarian steroid regulation of monoamine oxidase-A and -B mRNAs in the macaque dorsal raphe and hypothalamic nuclei. Psychopharmacology (Berl) 160, 271-282.

Jovicich, J., Czanner, S., Han, X., Salat, D., van der Kouwe, A., Quinn, B., Pacheco, J., Albert, M., Killiany, R., Blacker, D., Maguire, P., Rosas, D., Makris, N., Gollub, R., Dale, A., Dickerson, B.C. Fischl, B., 2009. MRI-derived measurements of human subcortical, ventricular and intracranial brain volumes: reliability effects of scan sessions, acquisition sequences, data analyses, scanner upgrade, scanner vendors and field strengths. Neuroimage 46, 177-192.

Kim-Cohen, J., Caspi, A., Taylor, A., Williams, B., Newcombe, R., Craig, I.W., Moffitt, T.E., 2006. MAOA, maltreatment, and gene-environment interaction predicting children's mental health: new evidence and a meta-analysis. Molecular Psychiatry 11, 903-913.

Kim, J. Shih, J.C. Chen, K, Chen, L, Bao, S., Maren, S, Anagnostaras, S.G, Fanselow, M.S. De Maeyer, E., Seif, I., Thompson, R.F., 1997. Selective enhancement of emotional, but not motor, learning in monoamine oxidase A-deficient mice. Proceedings of the National Academy of Sciences of the United States of America 94, 5929-5933.

Labate, A., Gambardella, A., Aguglia, U., Condino, F., Ventura, P., Lanza, P., Quattrone, A., 2010. Temporal lobe abnormalities on brain MRI in healthy volunteers: a prospective case-control study. Neurology 74, 553-557.

Lesch, K.P., Merschdorf, U., 2000. Impulsivity, aggression, and serotonin: a molecular psychobiological perspective. Behavioral Sciences \& the Law 18, 581-604.

Makris, N., Gasic, G.P., Kennedy, D.N., Hodge, S.M., Kaiser, J.R., Lee, M.J., Kim, B.W., Blood, A.J., Evins, A.E., Seidman, L.J., Iosifescu, D.V., Lee, S., Baxter, C., Perlis, R.H., Smoller, J.W., Fava, M., Breiter, H.C. 2008. Cortical thickness abnormalities in cocaine addiction-a reflection of both drug use and a pre-existing disposition to drug abuse? Neuron 60, 174-188.

Marenco, S., Radulescu, E., 2010. Imaging genetics of structural brain connectivity and neural integrity markers. Neuroimage $53,848-856$

Mattay, V., Goldberg, T.E., Sambataro, F., Weinberger, D.R., 2008. Brain longevity and normal cognitive aging: insights from imaging genetics. Biological Psychology 79, 9-22.

Measso, G., Cavarzeran, F., Zappalà, G., Lebowitz, B.D., Crook, T.H., Pirozzolo, F.J., Amaducci, L.A., Massari, D., Grigoletto, F., 1993. The Mini-Mental State Examination: normative study of a random sample of Italian population. Developmental Neuropsychology 9, 77-85.

Meyer-Lindenberg, A., Buckholtz, J.W., Kolachana, B., Hariri, A., Pezawas, L., Blasi, G., Wabnitz, A., Honea, R., Verchinski, B., Callicott, J.H., Egan, M., Mattay, V., Weinberger, D.R., 2006. Neural mechanisms of genetic risk for impulsivity and violence in humans. Proceedings of the National Academy of Sciences of the United States of America 103, 6269-6274.

Monuteaux, M.C., Seidman, L.J., Faraone, S.V., Makris, N., Spencer, T., Valera, E., Brown, A., Bush, G., Doyle, A.E., Hughes, S., Helliesen, M., Mick, E., Biederman, J., 2008. A preliminary study of dopamine D4 receptor genotype and structural brain alterations in adults with ADHD. American Journal of Medical Genetics. Part B: Neuropsychiatric Genetics 147, 1436-1441.

Morey, R.A., Petty, C.M., Xu, Y., Hayes, J.P., Wagner 2nd, H.R., Lewis, D.V., LaBar, K.S. Styner, M., McCarthy, G., 2009. A comparison of automated segmentation and manual tracing for quantifying hippocampal and amygdala volumes. Neuroimage $45,855-866$

Passamonti, L., Cerasa, A., Gioia, M.C., Magariello, A., Muglia, M., Quattrone, A., Fera, F., 2008. Genetically dependent modulation of serotonergic inactivation in the human prefrontal cortex. Neuroimage 40, 1264-1273.

Passamonti, L., Fera, F., Magariello, A., Cerasa, A., Gioia, M.C., Muglia, M., Nicoletti, G., Gallo, O., Provinciali, L., Quattrone, A., 2006. Monoamine oxidase-a genetic variations influence brain activity associated with inhibitory control: new insight into the neural correlates of impulsivity. Biological Psychiatry 59, 334-340.

Sabol, S.Z., Hu, S., Hamer, D., 1988. A functional polymorphism in the monoamine oxidase A gene promoter. Human Genetics 103, 273-279

Shih, J.C., Chen, K., 1999. MAO-A and -B gene knock-out mice exhibit distinctly different behaviour. Neurobiology 7, 235-246.

Soloff, P., Nutche, J., Goradia, D., Diwadkar, V., 2008. Structural brain abnormalities in borderline personality disorder: a voxel-based morphometry study. Psychiatry Research 164, 223-236.

Tisserand, D.J., Pruessner, J.C., Sanz Arigita, E.J., van Boxtel, M.P.J., Evans, A.C., Jolles, J., Uylings, H.B., 2002. Regional frontal cortical volumes decrease differentially in aging: an MRI study to compare volumetric approaches and voxel-based morphometry. Neuroimage 17, 657-669.

Walhovd, K., Fjell, A., Reinvang, I., Lundervold, A., Dale, A., Eilertsen, D.E., Quinn, B.T., Salat, D., Makris, N., Fischl, B., 2005. Effects of age on volumes of cortex, white matter and subcortical structures. Neurobiology of Aging 26, 1261-1270.

Zetzsche, T., Preuss, U.W., Bondy, B., Frodl, T., Zill, P., Schmitt, G., Koutsouleris, N., Rujescu, D., Born, C., Reiser, M., Möller, H.J., Meisenzahl, E.M., 2008. 5-HT1A receptor gene $\mathrm{C}-1019 \mathrm{G}$ polymorphism and amygdala volume in borderline personality disorder. Genes, Brain, and Behavior 7, 306-313. 